\title{
High-pressure synchrotron Mössbauer and X-ray diffraction studies: exploring the structure-related valence fluctuation in $\mathrm{EuNi}_{2} \mathbf{P}_{2}$
}

Chunyu $\mathrm{Li}^{\mathrm{a}}{ }^{\mathrm{b}}$, Zhenhai $\mathrm{Yu}^{\mathrm{a}, \mathrm{b}, *}$, Wenli Bi ${ }^{\mathrm{c}, \mathrm{d}}$, Jiyong $\mathrm{Zhao}^{\mathrm{c}}$, Michael Y. $\mathrm{Hu}^{\mathrm{c}}$, Jinggeng Zhao ${ }^{\mathrm{b}}$, Wei

$\mathrm{Wu}^{\mathrm{e}}$, Jianlin Luo ${ }^{\mathrm{e}, \mathrm{f}}$, Hao Yan ${ }^{\mathrm{a},{ }^{*}}$, Esen E. Alp ${ }^{\mathrm{c}}$, and Haozhe Liu ${ }^{\mathrm{a}, \mathrm{b}, *}$

${ }^{\mathrm{a}}$ Center for High Pressure Science and Technology Advanced Research, Shanghai 201203, China

${ }^{\mathrm{b}}$ Natural Science Research Center, Academy of Fundamental and Interdisciplinary Sciences, Harbin Institute of Technology, Harbin 150080, China

${ }^{c}$ Advanced Photon Source, Argonne National Laboratory, Argonne, IL 60439, USA

${ }^{\mathrm{d}}$ Department of Geology, University of Illinois at Urbana-Champaign, Urbana, IL 61801, USA

${ }^{\mathrm{e} B e i j i n g ~ N a t i o n a l ~ L a b ~ f o r ~ C o n d e n s e d ~ M a t t e r ~ P h y s i c s, ~ I n s t i t u t e ~ o f ~ P h y s i c s, ~ C h i n e s e ~ A c a d e m y ~ o f ~}$ Sciences, Beijing 100190, China

${ }^{\mathrm{f}}$ Collaborative Innovation Center of Quantum Matter, Beijing 100190, China

* Corresponding author, Tel./fax: 86-21-80177069

E-mail address: yuzh@hpstar.ac.cn (Zhenhai Yu), yanhao@hpstar.ac.cn (Hao Yan), haozhe.liu@hpstar.ac.cn (Haozhe Liu)

\section{Keywords:}

$\mathrm{ThCr}_{2} \mathrm{Si}_{2}$-type phosphides; Structural stability; Electronic phase transitions; High-pressure. 


\section{Abstract}

The high pressure effect on valence fluctuation of the $\mathrm{ThCr}_{2} \mathrm{Si}_{2}$-type intermetallic compound $\mathrm{EuNi}_{2} \mathrm{P}_{2}$ has been investigated using in situ synchrotron Mössbauer spectroscopy (SMS). The isomer shift of ${ }^{151} \mathrm{Eu}$ in $\mathrm{EuNi}_{2} \mathrm{P}_{2}$ increases monotonically with increasing pressure up to $50 \mathrm{GPa}$, suggesting a valence transition of the Eu from mixed toward trivalent. The synchrotron angle-dispersive X-ray diffraction (AD-XRD) experiment shows that $\mathrm{EuNi}_{2} \mathrm{P}_{2}$ remains in the tetragonal structure up to $32.5 \mathrm{GPa}$ at room temperature. We propose that the evolutions of bonding distance with pressure have an obvious effect on the valence fluctuation. 


\section{Introduction}

The Eu-based intermetallic compounds $\mathrm{RET}_{2} \mathrm{X}_{2}(\mathrm{RE}=$ rare earth, $\mathrm{T}=$ transition metal, $\mathrm{X}=s p$-element) crystallizing in the $\mathrm{ThCr}_{2} \mathrm{Si}_{2}$ structure present many unusual properties such as the intermediate valences or the valence fluctuations [1]. The former corresponds to quantum mixing of two valence states due to overlapping of localized f-electrons and delocalized valence electrons. The latter can be considered as thermal fluctuations between two integer valence states. Among these compounds, $\mathrm{EuNi}_{2} \mathrm{P}_{2}$ is a homogeneously mixed-valency phosphide at ambient conditions. By Mössbauer and X-ray absorption spectroscopic studies, Nagarajan and co-workers have discovered an unusual valence-fluctuating phenomenon of $\mathrm{EuNi}_{2} \mathrm{P}_{2}$ that the average valency $\bar{v}$ of Eu in $\mathrm{EuNi}_{2} \mathrm{P}_{2}$ is nearly temperature-independent and the value maintains at about 2.5 even when $\mathrm{T} \rightarrow 0[2,3]$. Besides, the $\bar{v}$ of the Eu in $\mathrm{EuNi}_{2} \mathrm{P}_{2}$ just depends slightly on the magnetic field (2.64 at $0 \mathrm{~T}$ and 2.61 at $40 \mathrm{~T}$ ) [4]. While the $\bar{v}$ of Eu in the homogeneously mixed valent compounds $\mathrm{EuCu}_{2} \mathrm{Si}_{2}$ and $\mathrm{EuPd}_{2} \mathrm{Si}_{2}$ has an strong temperature dependence, and the $\bar{v}$ of Eu can change from divalency to trivalency with the temperature increasing over a wide range ( 0 to $800 \mathrm{~K}$ for $\mathrm{EuCu}_{2} \mathrm{Si}_{2}$ and $100-200 \mathrm{~K}$ in $\mathrm{EuPd}_{2} \mathrm{Si}_{2}$ ) [5]. It should be noticed that the change of $\bar{v}$ of Eu in $\mathrm{EuNi}_{2} \mathrm{P}_{2}$ can be effectively enhanced with the combination of temperature and pressure (up to $9 \mathrm{GPa}$ and down to $4.2 \mathrm{~K}$ ) [5], which implies the important role of the pressure on the valence fluctuation. And it suggests that pushing the pressure further, a more abnormal and fascinating valence changing may be detected.

The valence fluctuation phenomenon was addressed from the viewpoint of strong 
electron correlations [6]. Guritanu et al. investigated the optical conductivity of the valence fluctuating compound $\mathrm{EuNi}_{2} \mathrm{P}_{2}$ which shows a strong similarity with that of many $\mathrm{Ce}$ - or $\mathrm{Yb}$ intermediate valent systems, claiming that the hybridization between the $4 \mathrm{f}$ level and the conduction electrons plays an important role for the valence change [7]. In the case where the two configurations $4 f^{7}\left(5 d^{0} 6 s^{2}\right)$ and $4 f^{6}\left(5 d^{1} 6 s^{2}\right)$ are very close in energy, one $4 f$ electron will fluctuate between its $4 f$ localized orbital and the $d s$ conduction band states at the Fermi level. Moreover, recent photoemission experiments suggest that there is also strong hybridization between the Eu $4 f$ electrons and the $\mathrm{Ni} 3 d$ electrons in $\mathrm{EuNi}_{2} \mathrm{P}_{2}[8]$. Eu valence in $\mathrm{EuNi}_{2} \mathrm{P}_{2}$ is $2.5-2.6$ due to the strong hybridization [5,9]. Very recently, Medvedev et al. investigated the electrical resistivity of mixed-valent $\mathrm{EuNi}_{2} \mathrm{P}_{2}$ at high pressure, and suggested that $\mathrm{Eu}$ is in the trivalent state at pressures above $24 \mathrm{GPa}$ according to the resistivity data [10].

The ternary $\mathrm{ThCr}_{2} \mathrm{Si}_{2}$-type intermetallics $\mathrm{EuCo}_{2} \mathrm{P}_{2}, \mathrm{EuFe}_{2} \mathrm{P}_{2}$ and $\mathrm{EuNi}_{2} \mathrm{P}_{2}$ are the $\mathrm{RET}_{2} \mathrm{X}_{2}$ prototype with space group I4/mmm (Pearson symbol TI10). The structural study on $\mathrm{EuCo}_{2} \mathrm{P}_{2}$ carried out by $\mathrm{C}$. Huhnt et al. revealed that a pressure-induced isostructural phase transition occurred at $3 \mathrm{GPa}$ [11]. The low-pressure (LP) and the high-pressure (HP) phases are within the same space group $14 / \mathrm{mmm}$. It was suggested that this phase transition was accompanied by a valence change of the Eu in $\mathrm{EuCo}_{2} \mathrm{P}_{2}$. The crystal structure of the $\mathrm{ThCr}_{2} \mathrm{Si}_{2}$-type phosphide $\mathrm{EuFe}_{2} \mathrm{P}_{2}$ was investigated by the single crystal diffraction technique [12]. A pressure-induced similar structural phase transition also occurred in $\mathrm{EuFe}_{2} \mathrm{P}_{2}$ [13,14]. Furthermore, many $\mathrm{RET}_{2} \mathrm{X}_{2}$-type intermetallics have been studied extensively to explore the correlation of 
superconductivity or magnetism and the corresponding structures [15-20]

Although many studies have claimed that high pressure can tune the valence of the $\mathrm{Eu}$ in $\mathrm{EuNi}_{2} \mathrm{P}_{2}$, the role of pressure playing in the valence fluctuation is still not clear. ${ }^{5,10}$ Detailed studies on the valence of the Eu in Eu-based systems are feasible by synchrotron Mössbauer spectroscopy (SMS) under high pressure [21,22]. In this work we have investigated the origin of the valency changing of the $\mathrm{Eu}$ in $\mathrm{EuNi}_{2} \mathrm{P}_{2}$ under high pressure through SMS combined with angle dispersive X-ray diffraction (AD-XRD). The mean of ${ }^{151}$ Eu can be estimated from the Mössbauer isomer shift (IS) [23]. The high pressure structure of $\mathrm{EuNi}_{2} \mathrm{P}_{2}$ has been studied by $\left.\mathrm{AD}-\mathrm{XRD}\right)$ and compared with the isostructural compounds $\mathrm{EuFe}_{2} \mathrm{P}_{2}$ and $\mathrm{EuCo}_{2} \mathrm{P}_{2}$. We discuss the relation between the valence fluctuation of Eu and the crystal structure and conclude that the pressure-induced valence change originates from the micro changes in crystal structure.

\section{Materials and methods}

The $\mathrm{EuNi}_{2} \mathrm{P}_{2}$ sample was synthesized using the tin-flux method. A full description can be found elsewhere [24]. The high pressure synchrotron SMS and AD-XRD experiments at room temperature with $\mathrm{EuNi}_{2} \mathrm{P}_{2}$ were carried out at the beamlines 3-ID-B and HPCAT 16-ID-B, the Advanced Photon Source (APS) of Argonne National Laboratory (ANL), respectively. $\mathrm{EuNi}_{2} \mathrm{P}_{2}$ samples in powder form were used in both The SMS and the AD-XRD experiments. A symmetric type diamond anvil cell (DAC) with a diamond culet size of $300 \mu \mathrm{m}$ was used to achieve high pressure.

The SMS experiment of $\mathrm{EuNi}_{2} \mathrm{P}_{2}$ was carried out up to the pressure of $50 \mathrm{GPa}$ at 
beamline 3-ID-B at room temperature. Re gasket was preindented to $45 \mu \mathrm{m}$ central thickness and a hole $110 \mu \mathrm{m}$ in diameter EDM-drilled as a sample chamber. Ruby spheres were loaded together with the sample in the gasket hole. The pressure was determined in situ by the standard ruby fluorescence method [25]. The X-ray beam at the nuclear resonance energy of $21.541 \mathrm{KeV}$ was focused to $\sim 15 \mu \mathrm{m}$ at the sample position by the Kirkpatrick-Baez mirrors.

In AD-XRD experiments, a T301 stainless steel was used as gasket material. The gasket with initial thickness of $300 \mu \mathrm{m}$ was pre-indented to $50 \mu \mathrm{m}$ and $120 \mu \mathrm{m}$ hole was drilled. Silicone oil was used as pressure transmitting medium. The AD-XRD experiments at room temperature were conducted with a monochromatic X-ray beam of $0.3679 \AA$, which was focused down using multilayer bimorph mirrors in a Kickpatrick-Baez configuration [26,27] to $10 \mu \mathrm{m} \times 10 \mu \mathrm{m}$ at the sample location in both horizontal and vertical directions. A pinhole placed before the sample position was used as a cleanup aperture for filtering out the tail of the X-ray beam. The pressures were determined by the ruby fluorescence method off line. The pressure difference before and after the collection of diffraction patterns was taken as the pressure uncertainty. $\mathrm{CeO}_{2}$ was used to calibrate the sample-detector distance and the orientation parameters of the detector. The two-dimensional XRD patterns were collected using a MAR345 image plate detector with an exposure time of $10 \mathrm{~s}$. Then the XRD images were integrated using the FIT2D program [28]. The Rietveld refinement on $\mathrm{XRD}$ patterns of $\mathrm{EuNi}_{2} \mathrm{P}_{2}$ was performed using the General Structure Analysis System (GSAS) program package [29,30]. 


\section{Results}

The IS values for $\mathrm{Eu}^{2+}$ systems are in the range of -8 to $-14 \mathrm{~mm} / \mathrm{s}$ (with respect to $\mathrm{EuF}_{3}$ ), whereas for $\mathrm{Eu}^{3+}$ systems, the IS is in the range of 0 to $+4 \mathrm{~mm} / \mathrm{s}$ [31]. The synchrotron Mössbauer spectra of ${ }^{151} \mathrm{Eu}$ for $\mathrm{EuNi}_{2} \mathrm{P}_{2}$ at various pressures are shown in Fig. 1. The time domain Mössbauer spectra of ${ }^{151} \mathrm{Eu}$ were collected with $\mathrm{EuF}_{3}$ and $\mathrm{EuS}$ as reference samples under high pressure. The SMS spectra are fitted using the software CONUSS [32]. The conventional Mössbauer absorption spectra were simulated using the hyperfine parameters obtained from fitting the time domain spectra. It is noticed that the energy domain spectra of $\mathrm{EuNi}_{2} \mathrm{P}_{2}$ have a single resonance peak without quadrupole splitting, which indicates that the crystallographic order of $\mathrm{EuNi}_{2} \mathrm{P}_{2}$ is at very high degree. The IS of the Eu ion in $\mathrm{EuNi}_{2} \mathrm{P}_{2}$ shown in Fig. 1 is $-5.96 \mathrm{~mm} / \mathrm{s}$ at $0 \mathrm{GPa}$ with $\mathrm{EuF}_{3}$ as reference suggesting $\mathrm{EuNi}_{2} \mathrm{P}_{2}$ is a homogeneous mixed-valence system at ambient conditions. The value of IS is in good agreement with reported value of $-6.3 \mathrm{~mm} / \mathrm{s}$ in Ref. [3,5]. The IS of the divalent $\mathrm{Eu}$ ion in $\mathrm{EuS}$ is $-12.03 \mathrm{~mm} / \mathrm{s}$ (with respect to $\mathrm{EuF}_{3}$ ). With increasing pressure the IS of the $\mathrm{Eu}$ ion in $\mathrm{EuNi}_{2} \mathrm{P}_{2}$ increases monotonically with increasing pressure, moving toward trivalent state of Eu. The high pressure values of IS in Eu are plotted in Fig. 2. It is shown that the IS of the Eu increases drastically with pressure in the range of 0 to $20 \mathrm{GPa}$. Above $20 \mathrm{GPa}$ the increase of IS slows down and IS reaches zero at $50 \mathrm{GPa}$, indicating that the $\bar{v}$ of $\mathrm{Eu}$ in $\mathrm{EuNi}_{2} \mathrm{P}_{2}$ becomes fully trivalent at about $50 \mathrm{GPa}$. Perscheid et al. show that the valence of Eu remains mixed under pressure up to 10 
GPa and at both $300 \mathrm{~K}$ and low tempearatures [5]. For $\mathrm{EuFe}_{2} \mathrm{P}_{2}$, a continuous valence change of $\mathrm{Eu}$ from $\mathrm{Eu}^{2+}$ to $\mathrm{Eu}^{3+}$ is accompanied by a second-order structural phase transition in the pressure range of $0 \sim 12 \mathrm{GPa}$. As for $\mathrm{EuCo}_{2} \mathrm{P}_{2}$, a sharp valence transition of $\mathrm{Eu}$ from $\mathrm{Eu}^{2+}$ to $\mathrm{Eu}^{3+}$ is accompanied by a pressure-induced first-order structural phase transition at $3 \mathrm{GPa}[33]$.

From the crystallographic point of view, the valence state can also be derived from the structural data alone via bond valence sum rules [34-36], which relates the interatomic distance and the coordination number to the corresponding element valence. However, Souza-Neto et al. studied Eu's valence in EuO under high pressure and found that the bond-valence sum rules fail to quantitatively describe the electronic valence behavior of $\mathrm{EuO}$ under high pressure [37]. For $\mathrm{EuFe}_{2} \mathrm{P}_{2}$ and $\mathrm{EuCo}_{2} \mathrm{P}_{2}$, their structural instability was intimately connected to the electronic and magnetic instabilities [38]. For $\mathrm{EuNi}_{2} \mathrm{P}_{2}$, it is unclear whether the same phenomenon exists. So it is necessary to investigate the detailed crystal structural change induced by pressure through XRD.

$\mathrm{EuNi}_{2} \mathrm{P}_{2}$ crystallizes in a body-centered tetragonal structure with two formulas per unit cell [39]. The schematic crystal structure and the Wyckoff positions of $\mathrm{EuNi}_{2} \mathrm{P}_{2}$ are shown in the inset of Fig. 2. The Wyckoff positions of $\mathrm{Eu}, \mathrm{Ni}$ and $\mathrm{P}$ atoms are located at $2 \mathrm{a}(0,0,0), 4 \mathrm{~d}(0,0.5,0.25)$ and $4 \mathrm{e}(0,0, z)$, respectively. The Eu atoms are located at the center of a polyhedron composed of the Ni and P atoms. The crystal structure of $\mathrm{EuNi}_{2} \mathrm{P}_{2}$ can be schematically described as an alternative stacking sequence of the positively charged $\mathrm{Eu}$ sheets and the negatively charged $\mathrm{Ni}_{2} \mathrm{P}_{2}$ blocks, 
which can be considered as consisting of the $\mathrm{NiP}_{4}$ tetrahedra along $c$ direction [40-44]. This interesting crystallography of the $\mathrm{AB}_{2} \mathrm{X}_{2}$-type compounds was highlighted by $\mathrm{R}$. Hoffmann and C. Zheng in 1985, who pointed out that the bonding between the A and the $\mathrm{B}_{2} \mathrm{X}_{2}$ layers is largely ionic. While in the $\mathrm{B}_{2} \mathrm{X}_{2}$ layers there are not only covalent $\mathrm{B}-\mathrm{X}$ bonding but also the metallic bonding $\mathrm{B}-\mathrm{B}$, and the $\mathrm{X}-\mathrm{X}$ bonding of two neighboring $\mathrm{B}_{2} \mathrm{X}_{2}$ layers varies from no bond to a fully formed $\mathrm{X}-\mathrm{X}$ single bond according to the variety of the transition metal B [45].

In the isostructural phosphides $\operatorname{EuT}_{2} \mathrm{P}_{2}(\mathrm{~T}=\mathrm{Fe}, \mathrm{Co}, \mathrm{Ni})$, the different atomic sizes of the $\mathrm{T}$ element are responsible for the different lattice parameters. So they are the ideal series for exploring the relation of the element valences and the corresponding lattice parameters. $\mathrm{AD}-\mathrm{XRD}$ experiment on $\mathrm{EuNi}_{2} \mathrm{P}_{2}$ was carried out under high pressure up to $32 \mathrm{GPa}$. The AD-XRD patterns are shown in Fig. 3. Up to $32 \mathrm{GPa}$ no new diffraction peaks were observed, showing the crystal structure is stable in this pressure range. All the Bragg reflections can be indexed by the space group I4/ $\mathrm{mmm}$ from ambient pressure to about $32 \mathrm{GPa}$. The unit cell volumes of $\mathrm{EuNi}_{2} \mathrm{P}_{2}$ are calculated from the refined lattice parameters in GSAS and shown in Fig. 4. At ambient pressure, the unit cell volume of $\mathrm{EuNi}_{2} \mathrm{P}_{2}$ is $147.2 \AA^{3}$, which is smaller than both $\mathrm{EuFe}_{2} \mathrm{P}_{2}$ and $\mathrm{EuCo}_{2} \mathrm{P}_{2}$. Shown in the inset of Fig. 4, the crystalline lattices of $\mathrm{EuNi}_{2} \mathrm{P}_{2}$ shrink quite uniformly, similar to the behavior observed in the high pressure collapsed tetragonal phases of the other related compounds.

\section{Discussion}


The valence of the Eu ion can change from $\mathrm{Eu}^{2+}$ to $\mathrm{Eu}^{3+}$ in both $\mathrm{EuFe}_{2} \mathrm{P}_{2}$ and $\mathrm{EuCo}_{2} \mathrm{P}_{2}$ under high pressure, accompanied by the pressure-induced second-order and first-order structural phase transitions, respectively [33]. However, the valence of the $\mathrm{Eu}$ ion in $\mathrm{EuNi}_{2} \mathrm{P}_{2}$ changes monotonically from a mixed valency to nearly full trivalency with increasing pressure up to $50 \mathrm{GPa}$ without any structural phase transition observed from the XRD patterns. The above phenomena can be addressed from the point of view of the atomic bonding. At ambient conditions, the $\mathrm{P}-\mathrm{P}$ distance of two adjacent $\mathrm{T}_{2} \mathrm{P}_{2}(\mathrm{~T}=\mathrm{Fe}, \mathrm{Co}, \mathrm{Ni})$ layers in $\mathrm{EuNi}_{2} \mathrm{P}_{2}$ is very different from the ones in $\mathrm{EuFe}_{2} \mathrm{P}_{2}$ and $\mathrm{EuCo}_{2} \mathrm{P}_{2}$, with the value being 2.371, 3.27 and $3.273 \AA$, respectively $[24,46]$. Only the $\mathrm{P}-\mathrm{P}$ distance in $\mathrm{EuNi}_{2} \mathrm{P}_{2}$ is close to the ideal P-P single bonding distance of $2.21 \AA$ [47]. It suggests the possible forming of the P-P covalent bonding in the direction normal to the layers in $\mathrm{EuNi}_{2} \mathrm{P}_{2}$ at ambient conditions. While the $\mathrm{P}$ atoms in two adjacent $\mathrm{T}_{2} \mathrm{P}_{2}$ layers in $\mathrm{EuFe}_{2} \mathrm{P}_{2}$ and $\mathrm{EuCo}_{2} \mathrm{P}_{2}$ are isolated from each other at ambient conditions, yielding divalent behavior in Eu. The chemical bonding in the ternary nickel phosphides $\mathrm{LnNi}_{2} \mathrm{P}_{2}$ was discussed on the basis of the Zintl-Klemm concept $[48,49]$, analogously to which, the valences of all the elements can be described as ionic formulations $\mathrm{Eu}^{2+} \mathrm{Fe}^{2+} \mathrm{Fe}^{2+} \mathrm{P}^{3-} \mathrm{P}^{3-}$ in $\mathrm{EuFe}_{2} \mathrm{P}_{2}$ and $\mathrm{Eu}^{2+} \mathrm{Co}^{2+} \mathrm{Co}^{2+} \mathrm{P}^{3-} \mathrm{P}^{3-}$ in $\mathrm{EuCo}_{2} \mathrm{P}_{2}$ (where bonding electrons are counted as belong to the more electronegative partner). It suggests that the formulation of the mixed valence in $\mathrm{EuNi}_{2} \mathrm{P}_{2}$ is in between two types: part is $\mathrm{Eu}^{2+} \mathrm{Ni}^{2+} \mathrm{Ni}^{2+} \mathrm{P}^{3-} \mathrm{P}^{3-}$ and part is $\mathrm{Eu}^{3+} \mathrm{Ni}^{1+} \mathrm{Ni}^{1+}\left[\mathrm{P}_{2}\right]^{5-}$ at ambient conditions. The P-P distance in $\mathrm{EuNi}_{2} \mathrm{P}_{2}$ becomes closer under high pressure. Finally, high pressure will turn the formulation of $\mathrm{EuNi}_{2} \mathrm{P}_{2}$ to the 
$\mathrm{Eu}^{3+} \mathrm{Ni}^{1+} \mathrm{Ni}^{1+}\left[\mathrm{P}_{2}\right]^{5-}$ type which means there still exists the unbonding status for the P-P interaction. For the $\mathrm{P}$ element which is the form $\left[\mathrm{P}_{2}\right]^{5-}$, the length of the $\mathrm{P}-\mathrm{P}$ bonding is roughly in between that for a single covalent bonding form $\left[\mathrm{P}_{2}\right]^{4-}$ and a non-bonding form $2 \mathrm{P}^{3-}$. The valency of the $\mathrm{Eu}$ changes from $\mathrm{Eu}^{2+}$ to $\mathrm{Eu}^{3+}$ and the valency of the $\mathrm{Ni}$ element changes from $\mathrm{Ni}^{2+}$ to $\mathrm{Ni}^{1+}$. It means that the $\mathrm{Ni}$ atoms finally possess nine unshared valence electrons in $3 \mathrm{~d}$ orbital to form a " $d$ " system, if the partial covalency of the Ni-P interactions is not considered [47].

Using the third-order Birch-Murnaghan equation [50], the ambient pressure isothermal bulk modulus and its derivative of $\mathrm{EuNi}_{2} \mathrm{P}_{2}$ were obtained by the volume-pressure data fitting in Fig. 4 , which are $B_{0}=154.9(6) \mathrm{GPa}$ and $B_{0}{ }^{\prime}=4.8(3)$, and the solid line in Fig. 4 is the fitting data. The present result of bulk modulus for $\mathrm{EuNi}_{2} \mathrm{P}_{2}$ was consistent with the reported literature data [10]. By using the high pressure energy dispersive XRD data in Ref. [11,13], the ambient pressure isothermal bulk moduli of the low pressure phases for $\mathrm{EuFe}_{2} \mathrm{P}_{2}$ and $\mathrm{EuCo}_{2} \mathrm{P}_{2}$ were estimated as $45 \mathrm{GPa}$ and $73 \mathrm{GPa}$, respectively. By contrast, $\mathrm{EuNi}_{2} \mathrm{P}_{2}$ exhibits much larger bulk modulus, which may origin from the much harder covalent P-P bonding existing in $\mathrm{EuNi}_{2} \mathrm{P}_{2}$.

The valence change in $\mathrm{EuNi}_{2} \mathrm{P}_{2}$ can be addressed from the aspect of the electronic structure. In the f-electron system, the mixed valency is mostly explained as the hybridization between the localized $f$ orbital of the rare earth or the actinide element and the itinerant delocalized $s, p, d$ valence electrons throughout the crystal lattice, which could result in many astonishing correlated phenomena [51]. In the 
homogeneous mixed-valence Eu-based compounds, the $4 f$ electrons of the Eu element have a dynamical fluctuation between localization and delocalization. For the Eu element in $\mathrm{EuNi}_{2} \mathrm{P}_{2}$, the $4 \mathrm{f}$ orbital fluctuates between $4 f^{6}$ and $4 f^{7}$. The valence of Eu in $\mathrm{EuNi}_{2} \mathrm{P}_{2}$ is changed under high pressure and reaches almost full trivalency from the mixed valent state. It means that the external pressure is a main driving force for immensely enhancing the electrons hybridization which is responsible for the atom bonding status in $\mathrm{EuNi}_{2} \mathrm{P}_{2}$. Furthermore, it is also indirectly claimed that even down to $T \rightarrow 0 \mathrm{~K}$ is still not enough for the Eu element to reach trivalency because of the more moderate effect of temperature than pressure on the volume of $\mathrm{EuNi}_{2} \mathrm{P}_{2}$. Besides, it should be noticed that the temperature and the composition dependences of the valence differ strongly between $\mathrm{Eu}$ based and $\mathrm{Ce} / \mathrm{Yb}$ based systems, while the pressure dependence of the valence in $\mathrm{EuNi}_{2} \mathrm{P}_{2}$ definitely display a similar characteristic with many $\mathrm{Ce} / \mathrm{Yb}$ based heavy fermion metals which are mainly dominated by the Kondo lattice/intermediate valence (KL/IV) scenario [52-54].

\section{Conclusions}

In summary, the valence change in $\mathrm{EuNi}_{2} \mathrm{P}_{2}$ has been discussed from the aspects of the crystal structure and electronic structure using the synchrotron Mössbauer and AD-XRD measurements. The synchrotron Mössbauer results suggest that in $\mathrm{EuNi}_{2} \mathrm{P}_{2}$ Eu's valence increases toward trivalent with increasing pressure and becomes fully trivalent around $50 \mathrm{GPa}$. AD-XRD experiments show no structural phase transition up to $32 \mathrm{GPa}$. It is claimed that the valence change of Eu is strongly correlated with P-P 
bonding and the electrons hybridization.

\section{Acknowledgements}

We thank Stanislav V. Sinogeikin (16-ID-B, APS, ANL) for experimental help. The High Pressure Collaborative Access Team (HPCAT) facility is supported by CIW, CDAC, UNLV and LLNL through funding from DOE-NNSA, DOE-BES and NSF. APS is supported by DOE-BES, under Contract No. DE-AC02-06CH11357. Support by Consortium for Materials Properties Research in Earth Sciences (COMPRES), the National Science Foundation (NSF) through Grant No. DMR-1104742 is gratefully acknowledged. This work was partially supported by National Natural Science Foundation of China (Grant No. 10904022), the National Basic Research Program of China (Grant Nos. 2011CB921700, No. 2015CB921300) and the Strategic Priority Research Program of the Chinese Academy of Sciences (XDB07020000). 


\section{Reference}

[1] N.B. Brandt, V.V. Moshchalkov, Adv. Phys. 33 (1984) 373.

[2] R. Nagarajan, E.V. Sampathkumaran, L.C. Gupta, R. Vijayaraghavan, V. Prabhawalkar, Bhaktdarshan, B.D. Padalia, Phys. Lett. A 84 (1981) 275.

[3] R. Nagarajan, G. K. Shenoy, L.C. Gupta, and E.V. Sampathkumaran, Phys. Rev. B 32 (1985) 2846.

[4] Y.H. Matsuda, Z.W. Ouyang, H. Nojiri, T. Inami, K. Ohwada, M. Suzuki, N. Kawamura, A. Mitsuda, and H. Wada, Phys. Rev. Lett. 103 (2009) 046402.

[5] B. Perscheid, E.V. Sampathkumaran, G. Kaindl, J. Magn. Magn. Mater. 47-48 (1985) 410.

[6] I. Serdons, S. Nasu, R. Callens, R. Coussement, T. Kawakami, J. Ladrière, S. Morimoto, T. Ono, K. Vyvey, T. Yamada, Y. Yoda, and J. Odeurs, Phys. Rev. B 70 (2004) 014109.

[7] V. Guritanu, S. Seiro, J. Sichelschmidt, N. Caroca-Canales, T. Iizuka, S. Kimura, C. Geibel, and F. Steglich, Phys. Rev. Lett. 109 (2012) 247207.

[8] S. Danzenbächer, D.V. Vyalikh, Yu. Kucherenko, A. Kade, C. Laubschat, N. Caroca-Canales, C. Krellner, C. Geibel, A.V. Fedorov, D.S. Dessau, R. Follath, W. Eberhardt, and S.L. Molodtsov, Phys. Rev. Lett. 102 (2009) 026403.

[9] R. Nagarajan, G.K. Shenoy, L.C. Gupta, E.V. Sampathkumaran, J. Magn. Magn. Mat. 47-48 (1985) 413.

[10] S.A. Medvedev, P. Naumov, O. Barkalov, C. Shekhar, T. Palasyuk, V. Ksenofontov, G. Wortmann and C. Felser, J. Phys.: Condens. Matter 26 (2014) 335701.

[11] C. Huhnt, W. Schlabitz, A. Wurth, A. Mewis, and M. Reehuis, Phys. Rev. B 56 (1997) 13796.

[12] M. Reehuis, W. Jeitschko, J. Phys. Chem. Solids 51 (1990) 961.

[13] C. Huhnt, W. Schlabitz, A. Wurth, A. Mewis, M. Reehuis, Physica B 252 (1998) 44.

[14] B. Ni, M.M. Abd-Elmeguid, H. Micklitz, J.P. Sanchez, P. Vulliet, and D. Johrendt, Phys. Rev. B 63 (2001) 100102(R).

[15] F. Steglich, J. Aarts, C.D. Bredl, W. Lieke, D. Meschede, W. Franz, and H. Schäfer, Phys. Rev. Lett. 43 (1979) 1892.

[16] G.W. Hull, J.H. Wernick, T.H. Geballe, J.V. Waszczak, and J.E. Bernardini, Phys. Rev. B 24 (1981) 6715.

[17] Marianne Rotter, Marcus Tegel, and Dirk Johrendt, Phys. Rev. Lett. 101 (2008) 107006.

[18] Y.Q. Chen, J. Luo, J.K. Liang, J.B. Li, G.H. Rao, J. Alloy. Compd. 489 (2010) 13.

[19] Z. Hossain, C. Geibel, F. Weickert, T. Radu, Y. Tokiwa, H. Jeevan, P. Gegenwart, and F. Steglich, Phys. Rev. B 72 (2005) 094411.

[20] H.S. Jeevan, C. Geibel, and Z. Hossain, Phys. Rev. B 73 (2006) 020407(R).

[21] E.E. Alp, W. Sturhahn, T. Toellner, Nucl. Instr. Meth. Phys. Res. B 97 (1995) 526.

[22] W. Bi, N.M. Souza-Neto, D. Haskel, G. Fabbris, E.E. Alp, J. Zhao, R.G. Hennig, M.M. Abd-Elmeguid, Y. Meng, R.W. McCallum, K. Dennis, and J.S. Schilling, Phys. Rev. B 85 (2012) 205134.

[23] W. Sturhahn, E.E. Alp, T.S. Toellner, P. Hession, M. Hu, J. Sutter, Hyperfine Interact. 113 (1998) 47.

[24] R. Marchand, W. Jeitschko, J. Solid State Chem. 24 (1978) 351.

[25] H.K. Mao, J.A. Xu, P. Bell, J. Geophys. Res. 91 (1986) 4673.

[26] S. Matsuyama, H. Mimura, H. Yumoto, K. Yamamura, Y. Sano, K. Endo, Y. Mori, Y. Nishino, K. Tamasaku, T. Ishikawa, M. Yabashi and K. Yamauchi, Rev. Sci. Instrum. 76 (2005) 083114.

[27] S. Matsuyama, H. Mimura, H. Yumoto, H. Hara, K. Yamamura, Y. Sano, K. Endo, Y. Mori, M. Yabashi, Y. Nishino, K. Tamasaku, T. Ishikawa and K. Yamauchi, Rev. Sci. Instrum. 77 (2006) 093107.

[28] A. Hammersley, S. Svensson, M. Hanfland, A. Fitch and D. Hausermann, High Pressure Res. 14 (1996) 235.

[29] A.C. Larson, R.B. Von Dreele, General Structure Analysis System (GSAS), Los Alamos National Laboratory Report LAUR (1994) 86-748.

[30] B.H. Toby, J. Appl. Crystallorg. 34 (2001) 210.

[31] J.G. Stevens, Hyperfine Interact. 13 (1983) 221.

[32] W. Sturhahn, Hyperfine Interactions 125 (2000) 149.

[33] M. Chefki, M.M. Abd-Elmeguid, H. Micklitz, C. Huhnt, W. Schlabitz, M. Reehuis, and W. Jeitschko, Phys. Rev. Lett. 80 (1998) 802.

[34] A. Jayaraman, A.K. Singh, A. Chatterjee, and S. Usha Devi, Phys. Rev. B 9 (1974) 2513.

[35] N.E. Brese, M. O'keeffe, Acta Crystallorg. B 47 (1991) 192. 
[36] I.D. Brown, D. Altermatt, Acta Crystallorg. B 41 (1985) 244.

[37] N.M. Souza-Neto, J. Zhao, E.E. Alp, G. Shen, S.V. Sinogeikin, G. Lapertot, and D. Haskel, Phys. Rev. Lett. 109 (2012) 026403.

[38] P.H. Andersson, L. Nordström, P. Mohn, and O. Eriksson, Phys. Rev. B 65 (2002) 174109.

[39] H.F. Braun, N. Engel, and E. Parthé, Phys. Rev. B 28 (1983) 1389.

[40] J. Leciejewicz, S. Siek, A. Szytuła, J. Less Common Met. 144 (1988) L9.

[41] I.R. Shein, A.L. Ivanovskii, Solid State Commun. 151 (2011) 1165.

[42] R. Marazza, R. Ferro, G. Rambaldi, G. Zanicchi, J. Less Common Met. 53 (1977) 193.

[43] A. Szytuła, B. Penc, M. Hofmann, J. Przewoźnik, Solid State Commun. 152 (2012) 1027.

[44] Z. Ban, M. Sikirica, Acta Crystallogr. 18 (1965) 594.

[45] R. Hoffmann, C. Zheng, J. Phys. Chem. 89 (1985) 4175.

[46] W. Jeitschko, \& B. Jaberg, J. Solid State Chem. 35 (1980) 312.

[47] H.G. Von Schnering, \& W. Hönle, Chem. Rev. 88 (1988) 243.

[48] W. Jeitschko, \& M. Reehuis, J. Phys. Chem. Solids 48 (1987) 667.

[49] H. Schäfer, B. Eisenmann, \& W. Müller, Angew. Chem. Int. Ed. 12 (1973) 694.

[50] F. Birch, Phys. Rev. 71 (1947) 809.

[51] C. Felser, S. Cramm, D. Johrendt, A. Mewis, O. Jepsen, G. Hohlneicher, W. Eberhardt and O.K. Andersen, Europhys. Lett. 40 (1997) 85.

[52] Q.M. Si, F. Steglich, Science 329 (2010) 1161.

[53] C.U. Segre, M. Croft, J.A. Hodges, V. Murgai, L.C. Gupta, and R.D. Parks, Phys. Rev. Lett. 49 (1982) 1947.

[54] S. Seiro and C. Geibel, J. Phys.: Condens. Matter 23 (2011) 375601. 
Figure captions

Fig. 1. Room temperature synchrotron Mössbauer spectra of ${ }^{151} \mathrm{Eu}$ for $\mathrm{EuNi}_{2} \mathrm{P}_{2}$ at various pressures.

Fig. 2. Isomer shift of ${ }^{151} \mathrm{Eu}$ ion in $\mathrm{EuNi}_{2} \mathrm{P}_{2}$ and $\mathrm{EuFe}_{2} \mathrm{P}_{2}$ versus pressure and temperature. The inset shows the schematic crystal structures of layered $\mathrm{EuNi}_{2} \mathrm{P}_{2}$ with the $\mathrm{ThCr}_{2} \mathrm{Si}_{2}$-type structure.

Fig. 3. Selected Angle dispersive $\mathrm{X}$-ray diffraction patterns of $\mathrm{EuNi}_{2} \mathrm{P}_{2}$ under various pressures.

Fig. 4. Pressure dependence of unit cell volume of $\mathrm{EuNi}_{2} \mathrm{P}_{2}$ on pressure fitted by Birch-Murnaghan equation of state. The inset shows the pressure dependence of lattice parameters of $\mathrm{EuNi}_{2} \mathrm{P}_{2}$. 


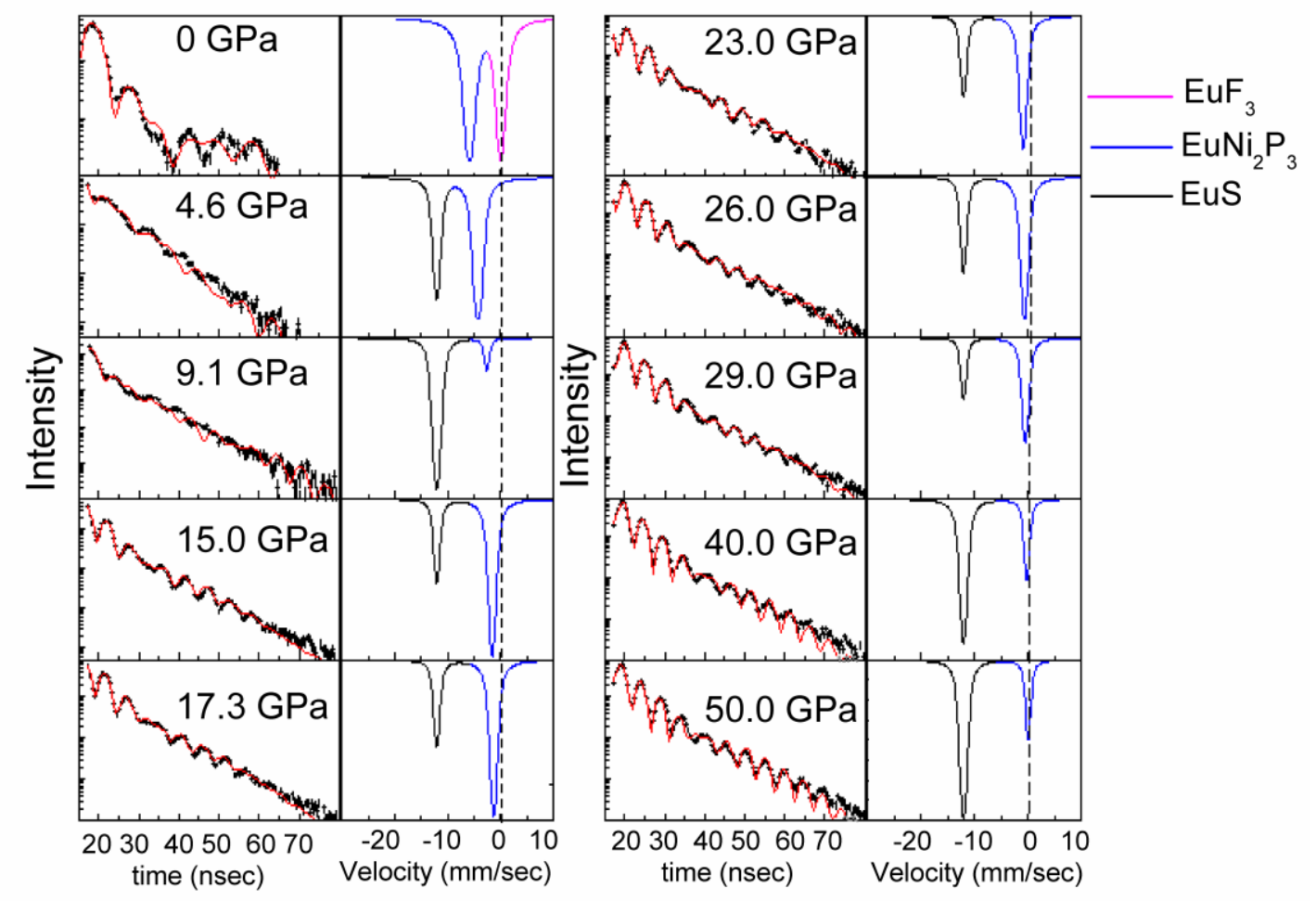




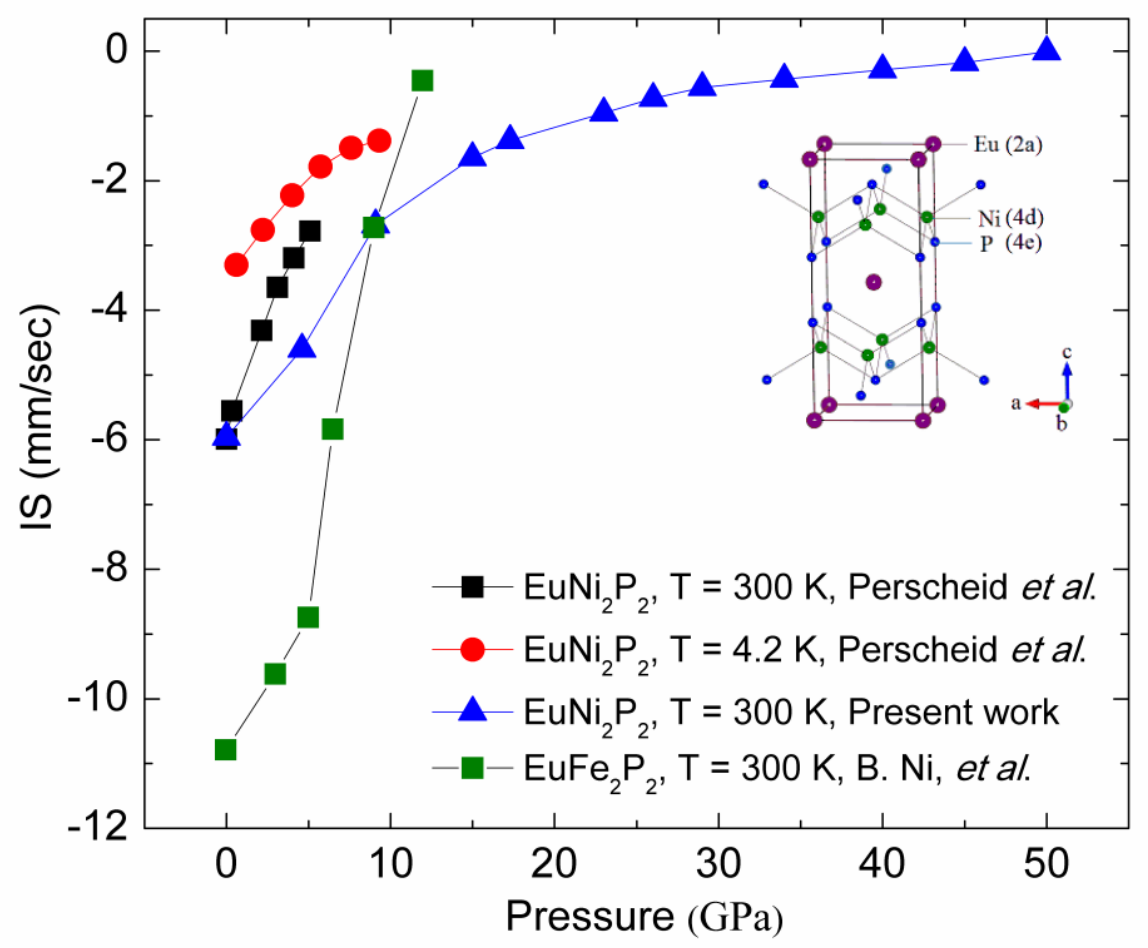




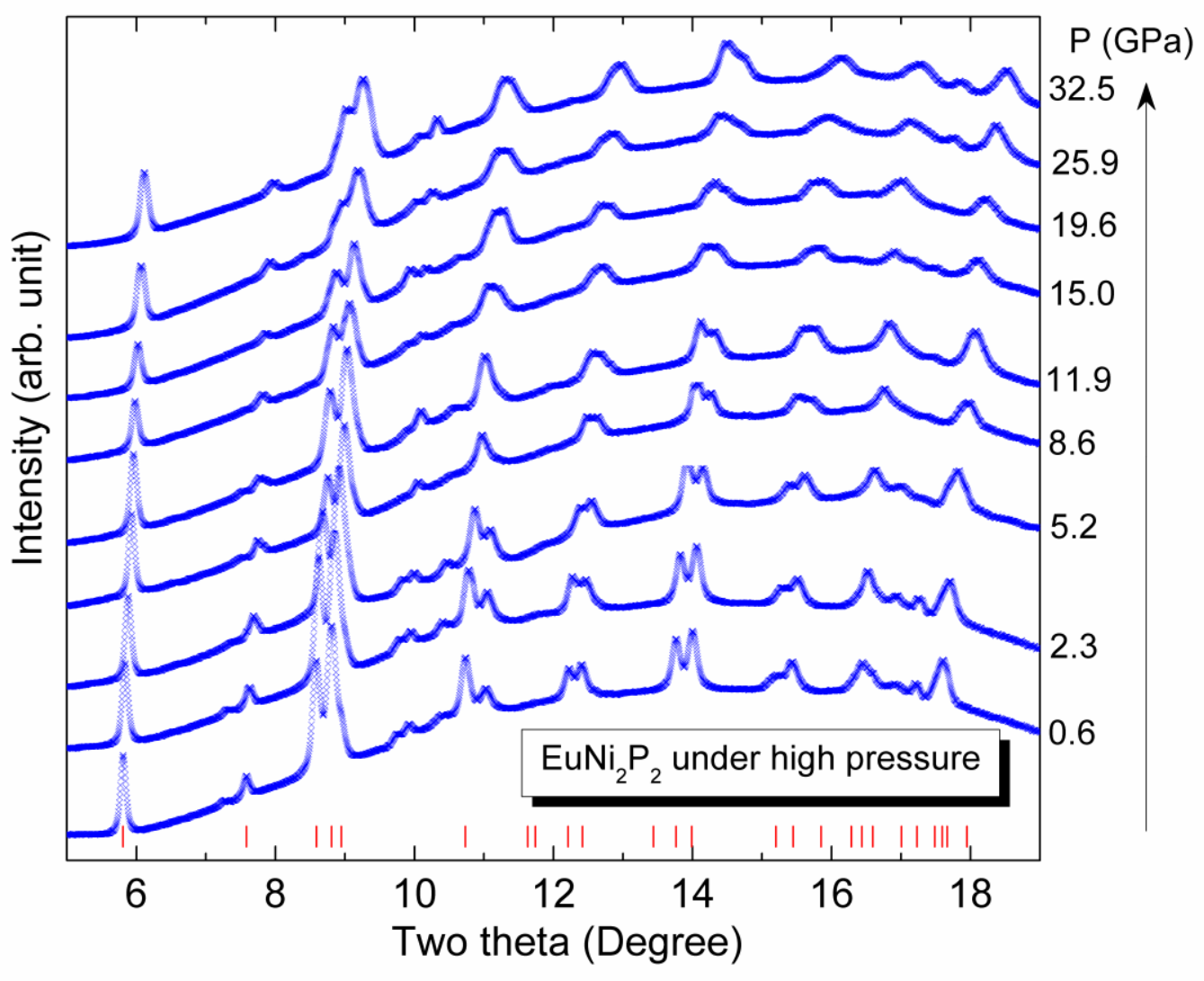




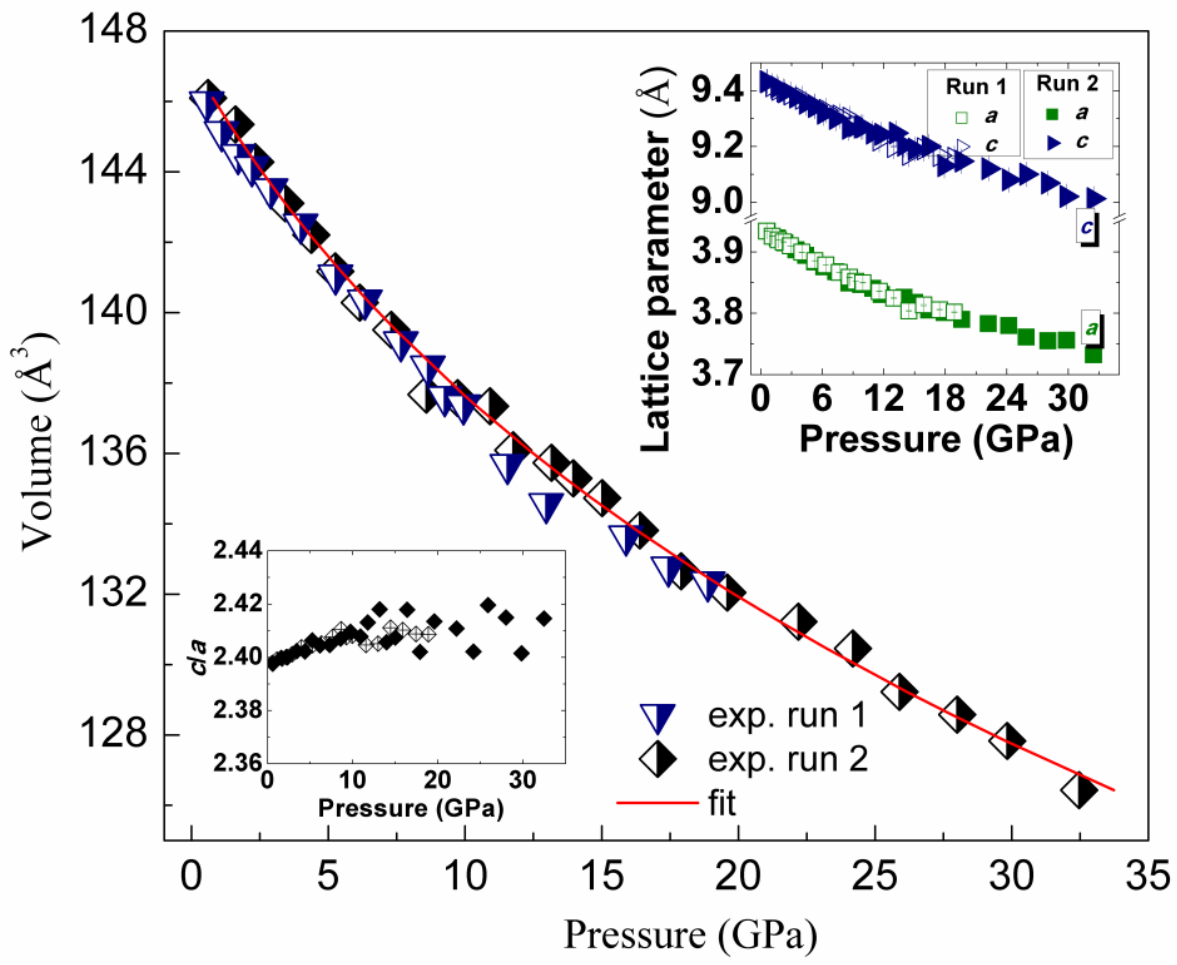

